\title{
Electronic structure and optical properties of lightweight metal hydrides
}

\author{
M. J. van Setten, ${ }^{1}$ V. A. Popa,${ }^{2}$ G. A. de Wijs, ${ }^{1}$ and G. Brocks ${ }^{2}$ \\ ${ }^{1}$ Electronic Structure of Materials, Institute for Molecules and Materials, Faculty of Science, Radboud University Nijmegen, \\ Toernooiveld 1, 6525 ED Nijmegen, The Netherlands \\ ${ }^{2}$ Computational Materials Science, Faculty of Science and Technology and MESA + Research Institute, University of Twente, \\ P.O. Box 217, 7500 AE Enschede, The Netherlands
}

(Received 1 September 2006; revised manuscript received 18 October 2006; published 4 January 2007)

\begin{abstract}
We study the dielectric functions of the series of simple hydrides $\mathrm{LiH}, \mathrm{NaH}, \mathrm{MgH}_{2}$, and $\mathrm{AlH}_{3}$, and of the complex hydrides $\mathrm{Li}_{3} \mathrm{AlH}_{6}, \mathrm{Na}_{3} \mathrm{AlH}_{6}, \mathrm{LiAlH}_{4}, \mathrm{NaAlH}_{4}$, and $\mathrm{Mg}\left(\mathrm{AlH}_{4}\right)_{2}$, using first-principles densityfunctional theory and $G W$ calculations. All compounds are large gap insulators with $G W$ single-particle band gaps varying from $3.5 \mathrm{eV}$ in $\mathrm{AlH}_{3}$ to $6.6 \mathrm{eV}$ in $\mathrm{LiAlH}_{4}$. Despite considerable differences between the band structures and the band gaps of the various compounds, their optical responses are qualitatively similar. In most of the spectra the optical absorption rises sharply above $6 \mathrm{eV}$ and has a strong peak around $8 \mathrm{eV}$. The quantitative differences in the optical spectra are interpreted in terms of the structure and the electronic structure of the compounds. In the simple hydrides the valence bands are dominated by the hydrogen atoms, whereas the conduction bands have mixed contributions from the hydrogens and the metal cations. The electronic structure of the aluminium compounds is determined mainly by aluminium hydride complexes and their mutual interactions.
\end{abstract}

DOI: 10.1103/PhysRevB.75.035204

PACS number(s): 71.20.Nr, 61.50.Lt, 61.66.Fn

\section{INTRODUCTION}

The large scale utilization of hydrogen as a fuel crucially depends on the development of compact hydrogen storage materials with a high mass content of hydrogen. ${ }^{1}$ Hydrides of group-I-III metals in the upper rows of the periodic table could meet this requirement. These metals are sufficiently light for their hydrides to have a large gravimetric hydrogen density; for instance, $\mathrm{MgH}_{2}$ contains $7.7 \mathrm{wt} \%$ hydrogen. One must be able to extract hydrogen at a moderate temperature, however, and therefore the metal hydride should be neither too stable nor too unstable. Simple metal hydrides do not satisfy this demand. For example, the binding energy of $\mathrm{MgH}_{2}$ is too large, ${ }^{2,3}$ whereas the binding energy of $\mathrm{AlH}_{3}$ is close to zero. ${ }^{4}$

This has stimulated research into binary intermetallic hydrides such as the alanates $M \mathrm{AlH}_{4}, M^{\prime}\left(\mathrm{AlH}_{4}\right)_{2}$, with $M$ and $M^{\prime}$ a light alkali and alkaline-earth metal, respectively. Some of the properties of these compounds have indeed improved as compared to the simple hydrides, but the compound that meets both the stability and the storage capacity demands has not been found yet. Whereas sodium alanate, $\mathrm{NaAlH}_{4}$, releases hydrogen in two reaction stages with enthalpies close to the ideal value, its active gravimetric hydrogen density is only $5.5 \mathrm{wt} \%$. ${ }^{1,5,6}$ Magnesium alanate, $\mathrm{Mg}\left(\mathrm{AlH}_{4}\right)_{2}$, and lithium alanate, $\mathrm{LiAlH}_{4}$, have a higher active gravimetric hydrogen density of 7.0 and $8.0 \mathrm{wt} \%$, respectively. However, they are not sufficiently stable with respect to decomposition into simpler hydrides. ${ }^{7-12}$

A suitable ternary intermetallic hydride might satisfy all requirements. The number of possible ternary compounds is very large, however, and searching for the optimal composition becomes very tedious, unless one uses a combinatorial approach. Such techniques have been proposed recently, in which thin films are grown with tunable composition gradients. ${ }^{13,14}$ The composition is then a function of the po- sition on the film. This avoids having to synthesize all compositions individually, but one still needs to be able to identify the most promising ones. It is proposed that identification can be based upon the optical properties of suitable metal hydrides being very different from those of their host metals. ${ }^{13}$ This has first been demonstrated conclusively for $\mathrm{YH}_{3},{ }^{15}$ and since then for a number of other socalled "switchable mirror" rare-earth and transition-metal compounds. ${ }^{16-22}$ The compounds that absorb the maximum amount of hydrogen become semiconductors or insulators.

If one applies this technique to group-I-III metal hydrides, it is relevant to know how the optical properties of these compounds depend on their composition and structure. In this paper we report a systematic first-principles study of the band gaps, the electronic structure, and the optical properties of group-I-III metal hydrides. Band gaps and singleparticle excitations are calculated within the $G W$ quasiparticle approach; optical excitations are obtained using the random-phase approximation (RPA). We focus upon a number of elements that are of interest for lightweight metal hydrides, i.e., $\mathrm{Li}, \mathrm{Na}, \mathrm{Mg}$, and $\mathrm{Al}$. In particular, we consider the series of simple metal hydrides $\mathrm{LiH}, \mathrm{NaH}, \mathrm{MgH}_{2}, \mathrm{AlH}_{3}$, and the binary metal hydrides $\mathrm{Li}_{3} \mathrm{AlH}_{6}, \mathrm{Na}_{3} \mathrm{AlH}_{6}, \mathrm{LiAlH}_{4}$, $\mathrm{NaAlH}_{4}$, and $\operatorname{Mg}\left(\mathrm{AlH}_{4}\right)_{2}{ }^{6,8,23-29}$ The trends in the optical spectra and electronic structure are discussed and interpreted in terms of the structure and bonding of the materials.

This paper is organized as follows. In Sec. II we outline the computational methods used in our study. The results are presented in Sec. III, first for the simple hydrides, then for the binary $\mathrm{M}_{3} \mathrm{AlH}_{6}$ hydrides, and finally for the $\mathrm{MAlH}_{4}$ alanates. Sections IV and V contain the discussion and a summary.

\section{COMPUTATIONAL METHODS}

The results discussed in this paper are obtained using a combination of density-functional theory (DFT) and $G W$ cal- 
culations. DFT is used at generalized gradient approximation (GGA) level to optimize the ground-state structure and obtain single-particle wave functions to be used in the calculation of the optical response. $G W$ is used to generate singleparticle excitation energies within the quasiparticle (QP) approximation, starting from DFT in the local-density approximation (LDA) wave functions and eigenvalues. The optical response is given by the frequency-dependent dielectric function, which is calculated within the random-phase approximation (RPA). In the latter we use single-particle wave functions and excitation energies and neglect exciton and local-field effects. The main difference between the DFT and the QP excitation spectra is the size of the fundamental band gap between occupied and unoccupied states, whereas the dispersion of the bands is quite similar. We use a scissors operator to the DFT eigenvalues to approximate QP excitation energies on a dense grid in the Brillouin zone, which is required to calculate the dielectric function.

\section{A. DFT ground-state calculations}

DFT total energies are calculated with the PW91 GGA functional $^{30}$ and the projector augmented wave (PAW) method, ${ }^{31,32}$ as implemented in the Vienna Ab initio Simulation Package (VASP). ${ }^{33-35}$ We use standard frozen core PAW potentials and a plane-wave basis set with a kinetic energy cutoff of $312 \mathrm{eV}$. The tetrahedron scheme is applied for the Brillouin zone integration using $\mathbf{k}$-point meshes with a spacing between 0.01 and $0.03 \AA^{-1}$. The cell parameters and the atomic positions within a unit cell are optimized by minimizing the total energy, except for the alkali alanates, where only the atomic positions are optimized and the cell parameters are taken from literature. For the alkali alanates various extensive studies have been reported on the crystal structure, both experimental and theoretical. For these materials the DFT-GGA crystal structure results agree well with experimental values, see, e.g., Refs. 36 and 37. Furthermore, calculations using slightly different lattice parameters agree well on the electronic structure of the materials. These optimized structures are used as input for the $G W$ calculations.

\section{B. $G W$ calculations}

DFT calculations generally give good results for groundstate properties, but not for excited states. The electronic band gap, for instance, can be underestimated by $\sim 50 \%$, and even more than that for small band-gap materials. This stems from an unjustified interpretation of the DFT (Kohn-Sham) eigenvalues as single-particle excitation energies. The latter can be obtained from the quasiparticle (QP) equation, which involves the nonlocal, energy dependent self-energy $\Sigma$,

$$
\begin{aligned}
& {\left[-\frac{1}{2} \nabla^{2}+v_{\text {ext }}(\mathbf{r})+V_{H}(\mathbf{r})\right] \psi_{n \mathbf{k}}(\mathbf{r})+\int d \mathbf{r}^{\prime} \Sigma\left(\mathbf{r}, \mathbf{r}^{\prime} ; \epsilon_{n \mathbf{k}}\right) \psi_{n \mathbf{k}}\left(\mathbf{r}^{\prime}\right)} \\
& \quad=\epsilon_{n \mathbf{k}} \psi_{n \mathbf{k}}(\mathbf{r}),
\end{aligned}
$$

where $v_{\text {ext }}$ stands for the sum of all nuclear or ionic potentials, $V_{H}$ is the electrostatic or Hartree potential resulting from the electrons, $\psi_{n \mathbf{k}}(\mathbf{r})$ is the QP wave function, and $\epsilon_{n \mathbf{k}}$ is the QP energy, i.e., the single-particle excitation energy. In practice Eq. (1) is solved using a number of approximations. The $G W$ technique approximates the self-energy $\Sigma$ by a dynamically screened exchange potential. A large variety of $G W$ implementations exist, in which quite different levels of approximation are used. Reviews of the $G W$ method can be found in Refs. 38, 40, and 39. We will explain our procedure in this section and benchmark it on simple hydrides in the next section.

The $G_{0} W_{0}$ approximation is commonly defined by constructing the self-energy $\Sigma$ from the orbitals and eigenvalues obtained in a DFT-LDA. ${ }^{38-41}$ If the QP and DFT-LDA wave functions do not differ significantly, i.e., $\psi_{n \mathbf{k}}(\mathbf{r}) \approx \psi_{n \mathbf{k}}^{\mathrm{LDA}}(\mathbf{r})$, then Eq. (1) is approximated by ${ }^{42,43}$

$$
h_{n \mathbf{k}}+\Sigma_{n \mathbf{k}}\left(\epsilon_{n \mathbf{k}}\right)=\epsilon_{n \mathbf{k}},
$$

where $\quad h_{n \mathbf{k}}=\left\langle\psi_{n \mathbf{k}}^{\mathrm{LDA}}\left|-\frac{1}{2} \nabla^{2}+v_{\text {ext }}+V_{H}\right| \psi_{n \mathbf{k}}^{\mathrm{LDA}}\right\rangle \quad$ and $\quad \Sigma_{n \mathbf{k}}$ $=\left\langle\psi_{n \mathbf{k}}^{\mathrm{LDA}}|\Sigma| \psi_{n \mathbf{k}}^{\mathrm{LDA}}\right\rangle$. Equation (2) is nonlinear in $\epsilon_{n \mathbf{k}}$ and it is solved by a root-searching technique. ${ }^{44}$ In principle it is possible to base a $G_{0} W_{0}$ calculation upon orbitals and eigenvalues of any independent particle Hamiltonian, derived, e.g., from Hartree-Fock or DFT-GGA. However, the most widely tested $G_{0} W_{0}$ approach uses DFT-LDA orbitals and eigenvalues as starting point, which is the approach we use here. Calculations within this scheme have been applied to a wide range of semiconductors and insulators. They lead to band gaps that are usually within $10 \%$ of the experimental values, although occasionally somewhat larger deviations are found. $38,40,39$

Since $G W$ calculations are computationally demanding, all electron calculations are generally possible only for relatively small unit cells. ${ }^{45}$ In order to decrease the computational demands pseudopotentials are used to represent the ion cores and only the valence electrons are treated explicitly. The effects of this approximation are discussed in the literature. ${ }^{38,40,45}$ In principle, an overlap between core and valence charge densities contributes to the screening, and thus to the self-energy. This contribution is neglected in a pseudopotential approach, but a simple estimate of its effect is made by adding

$$
\left(V_{x c}\left[\rho_{v}+\rho_{c}\right]-V_{x c}\left[\rho_{v}\right]\right)_{n \mathbf{k}},
$$

to the QP energies, where $V_{x c}$ is the LDA exchangecorrelation potential, $\rho_{c, v}$ are the core and valence charge densities, and $n \mathbf{k}$ indicates the expectation value with respect to an LDA wave function as in Eq. (2) ${ }^{46,47}$ We will benchmark the effects of the pseudopotential approximation on the quasiparticle gaps of hydrides in the next section.

The QP equation, Eq. (1), is not related to DFT, but the scheme outlined above depends on LDA eigenvalues and wave functions through the $G_{0} W_{0}$ approximation for the selfenergy and through the approximation represented by Eq. (2). The dependence on LDA eigenvalues can be avoided by constructing the self-energy $(G W)$ from QP energies and solve the QP equation self-consistently. We have previously observed that self-consistency on the eigenvalues is in fact vital to obtain good results for small band-gap semiconductors that are incorrectly described by LDA as being metallic. ${ }^{46,47}$ For large band-gap materials, however, this 
self-consistency does not improve upon the $G_{0} W_{0}$ results. ${ }^{48}$ The dependence on LDA wave functions can be relaxed by solving Eq. (1) instead of Eq. (2). However, for large bandgap materials this changes the results only marginally. ${ }^{48}$ The dependence of the self-energy on the LDA wave functions is not that easily avoided. Self-consistency applied to QP wave functions worsens the results as compared to the $G_{0} W_{0}$ approximation. ${ }^{48}$

Since all hydrides considered in this paper turn out to be large band-gap insulators, we use the $G_{0} W_{0}$ approximation to calculate the QP spectrum. Starting from the optimized structures we generate wave functions and eigenvalues from an LDA calculation with norm-conserving pseudopotentials and a plane-wave kinetic energy cutoff of $748 \mathrm{eV} .{ }^{49}$ The selfenergy $G_{0} W_{0}$ is calculated using the real-space, imaginary time formalism. ${ }^{47,50-52}$ We include 350 LDA states, use a real space grid mesh with a typical spacing of $0.3-0.4 \AA$ and an interaction cell parameter of $\sim 25 \AA$. The QP equation is solved in the approximation represented by Eq. (2). We estimate that with these parameters QP band gaps are converged numerically to within $\pm 0.02 \mathrm{eV}$.

\section{Macroscopic dielectric function}

Optical excitations are two-particle excitations, but neglecting excitonic effects they can be approximated by transitions between single-particle states. Experimentally, the binding energy of the lowest-lying exciton in $\mathrm{LiH}$ is less than $0.05 \mathrm{eV} .{ }^{53,54}$ In this paper we assume that excitonic effects can be neglected. In addition we neglect local-field effects.

If we consider quasiparticles as independent particles, then the imaginary part of the macroscopic dielectric function obtains the simple form ${ }^{55-57}$

$$
\begin{aligned}
\varepsilon^{(2)}(\hat{\mathbf{q}}, \omega)= & \frac{8 \pi^{2} e^{2}}{V} \lim _{|\mathbf{q}| \rightarrow 0} \frac{1}{|\mathbf{q}|^{2}} \sum_{\mathbf{k} v c} \\
& \times\left|\left\langle u_{c \mathbf{k}+\mathbf{q}} \mid u_{v \mathbf{k}}\right\rangle\right|^{2} \delta\left(\epsilon_{c \mathbf{k}+\mathbf{q}}-\epsilon_{v \mathbf{k}}-\hbar \omega\right),
\end{aligned}
$$

where $\hat{\mathbf{q}}$ gives a direction, $v \mathbf{k}(c \mathbf{k})$ label single-particle states that are occupied (unoccupied) in the ground state, and $\epsilon, u$ are the single-particle energies and the translationally invariant parts of the wave functions; $V$ is the volume of the unit cell. We have assumed spin degeneracy.

Almost all optical data on hydrides are obtained on microor nanocrystalline samples whose crystallites have a significant spread in orientation. The most relevant quantity then is the directionally averaged dielectric function, i.e., $\varepsilon^{(2)}(\omega)$ averaged over $\hat{\mathbf{q}}$. Eq. (4) involves calculating $u_{c \mathbf{k}+\mathbf{q}}$ for small $\mathbf{q}$ and each $\mathbf{k}$ and extrapolating to $\mathbf{q}=0$. Details on the implementation can be found in Refs. 58 and 59.

The summation over the Brillouin zone in Eq. (4) is performed using a weighted tetrahedron scheme. ${ }^{60}$ We found that this scheme allows for a faster convergence with respect to the number of $\mathbf{k}$ points than various smearing methods. To calculate the dielectric tensor, we use the same plane-wave kinetic energy cutoff and k-point mesh as for the DFT-GGA calculations. The number of empty bands included is sufficiently large as to describe all transitions up to at least $16 \mathrm{eV}$.
If the imaginary part of the dielectric function, $\varepsilon^{(2)}(\omega)$, is calculated for all frequencies $\omega$, then the real part, $\varepsilon^{(1)}(\omega)$, can be obtained by a Kramers-Kronig transform. The static component $\varepsilon^{(1)}(0)=\varepsilon^{\infty}$ can also be calculated using densityfunctional perturbation theory. Since the latter calculation includes local-field effects, comparing $\varepsilon^{\infty}$ obtained with the two techniques is one indication for the importance of these effects. $^{58}$

In order to produce the right band gap one should use the $G W$ QP energies in Eq. (4). The k-point mesh used in an ordinary $G W$ calculation is not sufficiently dense to obtain an accurate dielectric function, however, and it is computationally very expensive to increase the density of this mesh. As we will show below, the main difference between the $G W$ and the GGA energies for the systems studied, is the size of the band gap between the occupied and the unoccupied states. The differences between the dispersions of the $G W$ and GGA bands are relatively small. Therefore we adopt a simple "scissors" operator approximation for the energy differences in Eq. (4), ${ }^{57}$

$$
\boldsymbol{\epsilon}_{c \mathbf{k}+\mathbf{q}}-\epsilon_{v \mathbf{k}}=\epsilon_{c \mathbf{k}+\mathbf{q}}^{G G A}-\epsilon_{v \mathbf{k}}^{G G A}+E_{g a p}^{G W}-E_{g a p}^{G G A} .
$$

\section{RESULTS}

\section{A. Simple hydrides}

\section{Test calculations}

Calculations on $\mathrm{LiH}$ and $\mathrm{NaH}$ are relatively straightforward because these compounds have a simple rocksalt structure. They can be used to benchmark the calculations. The calculated single-particle band gaps of $\mathrm{LiH}$ and $\mathrm{NaH}$ are listed in Table I. As is usual, DFT severely underestimates the gap, with LDA giving smaller values than GGA. Our calculated $G W$ gaps for $\mathrm{LiH}$ and $\mathrm{NaH}$ are close to those obtained in recent PAW all-electron $G_{0} W_{0}$ calculations (based upon LDA orbitals and eigenvalues). ${ }^{61,62}$ As stated in the previous section, our calculations use pseudopotentials and take into account explicitly the valence electrons only. The $G W$ band gaps as calculated from the QP energies obtained by solving Eq. (2), are indicated by $E_{g}^{G W}$ in Table I. They are somewhat larger than the PAW values. If one applies the core correction of Eq. (3), our $G W$ band gaps become somewhat smaller than the PAW values, as shown by the column marked $E_{g}^{G W \text {,core }}$ in Table I. The differences between the pseudopotential and the PAW $G W$ gaps are small, however, i.e., of the order of 2-4\% and the PAW values are

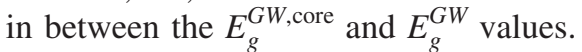

The band gap of LiH given in Ref. 54 has been calculated using the rather crude COSHEX approximation, which is known to lead to a much higher gap. ${ }^{61}$ The value given in Ref. 63 is much higher than that obtained in other $G W$ calculations, including ours, for which we have no explanation. The experimental band gap of LiH is higher than the calculated $G W$ values,${ }^{53}$ but the difference is within the usual $5-10 \% .{ }^{38-40}$ To our knowledge no experimental data are available for $\mathrm{NaH}$.

The band gap of $\mathrm{MgH}_{2}$ is calculated for the optimized rutile or $\alpha$ structure, ${ }^{7}$ which is the most stable structure at 
TABLE I. Single-particle band gaps $E_{g}(\mathrm{eV})$ of simple hydrides from DFT (GGA and LDA) and $G W$ calculations. $E_{g}^{G W \text {,core }}$ refers to applying the correction of Eq. (3).

\begin{tabular}{lccccc}
\hline \hline & $E_{g}^{G G A}$ & $E_{g}^{L D A}$ & $E_{g}^{G W}$ & $E_{g}^{G W, \text { core }}$ & $G W$ lit. \\
\hline $\mathrm{LiH}$ & 3.00 & 2.61 & 4.75 & 4.54 & $4.64,{ }^{\mathrm{a}} 5.24$, , $^{\mathrm{b}} 5.37^{\mathrm{c}}$ \\
& & & & $4.99^{\text {expt. } \mathrm{d}}$ \\
$\mathrm{NaH}$ & 3.79 & 3.42 & 5.87 & 5.50 & $5.68^{\mathrm{e}}$ \\
$\mathrm{MgH}_{2}$ & 3.79 & 3.36 & 5.64 & 5.32 & $5.25,{ }^{\mathrm{f}} 5.58^{\mathrm{g}}$ \\
$\mathrm{AlH}_{3}$ & 2.18 & 1.79 & 4.31 & 3.54 & \\
\hline \hline
\end{tabular}

aPAW, Ref. 61.

${ }^{\mathrm{b}}$ COHSEX, Ref. 54.

${ }^{\mathrm{c}}$ Reference 63.

${ }^{\mathrm{d}}$ Experimental gap at $T=4.2 \mathrm{~K}$, Ref. 53.

room temperature and ambient pressure. ${ }^{66}$ The $E_{g}^{G W \text {,core }}$ value we obtain is very close to that cited in Ref. 64 . A recently obtained PAW value for the band gap of $\mathrm{MgH}_{2}$ is again in between our $E_{g}^{G W, \text { core }}$ and $E_{g}^{G W}$ values. ${ }^{65}$ For $\mathrm{AlH}_{3}$ no other data are available to our knowledge. One can observe that core effects are relatively large in this compound.

In the following we will use the $E_{g}^{G W \text {,core }}$ values. The validity of using the scissors operator approximation for calculating the optical response, see Eq. (5), is illustrated by comparing bandwidths calculated with DFT and $G W$. The valence-band widths are given in Table II. The difference between the $G W$ and the LDA values is within $3 \%$ and the difference between the $G W$ and the GGA values is within $10 \%$. Note that the latter is on the same scale as the difference between the LDA and the GGA values. This accuracy is acceptable for our purposes. We have also checked in more detail that the dispersions of the individual bands in the DFT and $G W$ band structures are very similar.

Table II also lists the static dielectric constant calculated with and without local-field effects. The small differences between these numbers give no indication for large localfield effects.

\section{2. $\mathrm{LiH}$ and $\mathrm{NaH}$}

The calculated optimized lattice parameters of $\mathrm{LiH}$ and $\mathrm{NaH}$ in the rocksalt structure are 4.02 and $4.83 \AA$, respectively. These values are somewhat smaller than the experimental lattice parameters of 4.09 and $4.91 \AA$ due to neglecting the zero-point motions of the hydrogen atoms, as discussed in Ref. 67.

TABLE II. Valence-band widths $(\mathrm{eV})$ from DFT (GGA and LDA) and $G W$ calculations. The directionally averaged real part of the static dielectric constant, calculated with $(L F E)$ and without local-field effects.

\begin{tabular}{lccccc}
\hline \hline & GGA & LDA & $G W$ & $\varepsilon_{L F E}^{\infty}$ & $\varepsilon^{\infty}$ \\
\hline $\mathrm{LiH}$ & 5.41 & 5.62 & 5.81 & 4.28 & 4.34 \\
$\mathrm{NaH}$ & 3.58 & 4.00 & 3.99 & 3.03 & 3.06 \\
$\mathrm{MgH}_{2}$ & 6.34 & 6.62 & 6.66 & 3.90 & 3.98 \\
$\mathrm{AlH}_{3}$ & 8.60 & 8.82 & 8.92 & 4.43 & 4.55 \\
\hline \hline
\end{tabular}

ePAW, Ref. 62.

${ }^{\mathrm{f}}$ Cited in Ref. 64.

gPAW, Ref. 65.

The band structures and the directionally averaged $\varepsilon^{(2)}(\omega)$ of $\mathrm{LiH}$ and $\mathrm{NaH}$ are shown in Fig. 1. The valence bands in both $\mathrm{LiH}$ and $\mathrm{NaH}$ are strongly dominated by hydrogen, which reflects the ionic character of the bonding. ${ }^{54,61-63}$ The conduction bands have a mixed hydrogen and cation character. The lattice parameter of $\mathrm{LiH}$ is significantly smaller than that of $\mathrm{NaH}$. Because of the smaller distance between the hydrogen atoms the bandwidths in $\mathrm{LiH}$ are generally larger than in $\mathrm{NaH}$. This is most easily observed in the valence band, whose dispersion is quite similar in $\mathrm{LiH}$ and $\mathrm{NaH}$, but the $(G W)$ valence-band width in $\mathrm{LiH}$ is $5.81 \mathrm{eV}$, whereas in $\mathrm{NaH}$ it is $3.99 \mathrm{eV}$.

The conduction bands of the two compounds are qualitatively different. In $\mathrm{LiH}$ the conduction-band minimum is at
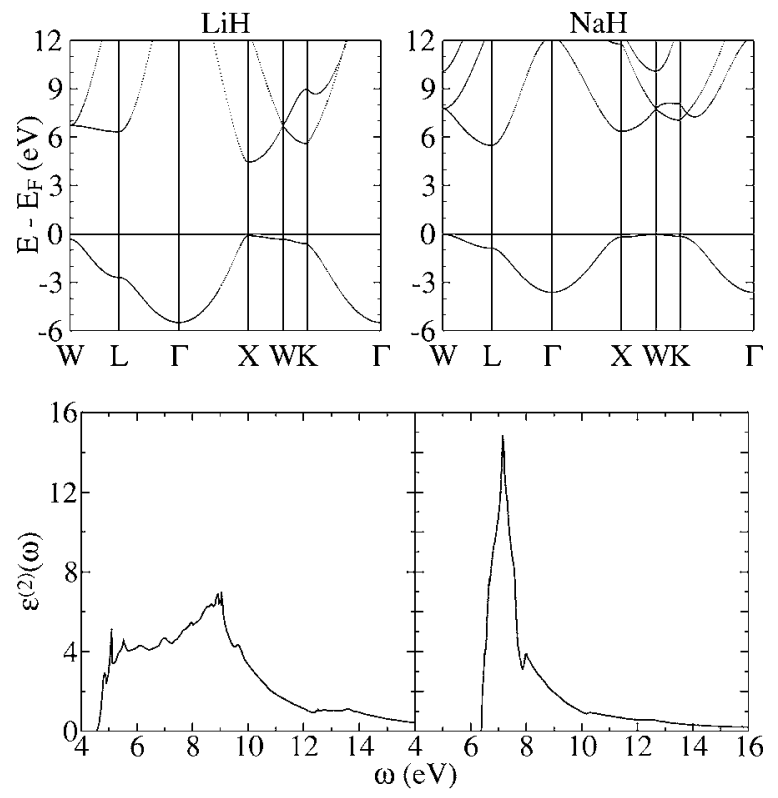

FIG. 1. Upper panels: electronic band structures of $\mathrm{LiH}$ and $\mathrm{NaH}$. The zero of the energy scale is at the top of the valence band. Lower panels: imaginary parts of the directionally averaged macroscopic dielectric functions of $\mathrm{LiH}$ and $\mathrm{NaH}$. The calculated optical gaps of $\mathrm{LiH}$ and $\mathrm{NaH}$ are 4.54 and $6.37 \mathrm{eV}$, respectively. Unless explicitly stated otherwise, the results presented in the figures are based upon GGA calculations modified by a scissors operator extracted from the $G W$ results. 
$X$, whereas in $\mathrm{NaH}$ it is at $L$, which causes the gap in $\mathrm{LiH}$ to be direct, whereas in $\mathrm{NaH}$ it is indirect. In $\mathrm{NaH}$ there is little participation of cation states in the lower-lying conduction bands. A calculation on an fcc lattice of $\mathrm{H}^{-}$ions with the $\mathrm{NaH}$ lattice parameter and a homogeneous background charge instead of the $\mathrm{Na}^{+}$cations, gives essentially the same band structure. In $\mathrm{LiH}$ the participation of the Li cations to the conduction band is larger. The conduction-band minimum at $X$ is lowered in energy because here the Li- $2 p$ state participates in a bonding combination with hydrogen states. Similarly, the conduction-band minimum at $L$ is raised in energy because the Li- $2 s$ state contributes to an antibonding combination with hydrogen states.

The differences between the band structures of $\mathrm{LiH}$ and $\mathrm{NaH}$ lead to markedly different dielectric functions, as is shown in the lower panel of Fig. 1. The calculated direct optical gap in $\mathrm{LiH}$ is $4.54 \mathrm{eV}$, whereas in $\mathrm{NaH}$ it is a much larger $6.37 \mathrm{eV}$. The main peak in the $\mathrm{NaH}$ spectrum originates from transitions at $L$ and $X$, whose onset is at comparable photon energies. Both valence and conduction bands of $\mathrm{NaH}$ have hydrogen character and the oscillator strength of these transitions is rather large. The result is a sharp and dominant peak just above the onset of the optically allowed transitions.

The optical spectrum of LiH has more structure. The onset at $4.54 \mathrm{eV}$ is due to transitions at $X$, and at a somewhat higher energy transitions near $K$ and $W$ contribute. At energies $\sim 9 \mathrm{eV}$ transitions at $L$ become allowed, which results in a peak in the dielectric function at that energy. Since the bands of $\mathrm{LiH}$ have a larger dispersion than those of $\mathrm{NaH}$, the optical response of $\mathrm{LiH}$ is spread out over a larger energy range.

\section{3. $\mathrm{MgH}_{2}$}

$\alpha-\mathrm{MgH}_{2}$ has the rutile structure, i.e., space group $\mathrm{P}_{2} / \mathrm{mnm}$ with $\mathrm{Mg}, \mathrm{H}$ atoms in $2 a, 4 f$ Wyckoff positions, respectively, and two formula units per unit cell. The optimized calculated lattice parameters are $a=4.52 \AA$ and $c$ $=3.01 \AA$, with the $\mathrm{H}$ atoms at $x=0.304$. This is in good agreement with the experimental values $a=4.50 \AA, c$ $=3.01 \AA$, and $x=0.304 .{ }^{68}$ The magnesium atoms are sixfold octahedrally coordinated by the hydrogen atoms at distances between 1.94 and $1.96 \AA$. Each $\mathrm{MgH}_{6}$ octahedron shares the hydrogen atoms at its corners with neighboring octahedra. Each hydrogen atom is shared by three octahedra and is therefore coordinated by three magnesium atoms.

The band structure of $\mathrm{MgH}_{2}$ is shown in Fig. 2, and agrees with the results in Refs. 65 and 69. There is a small hybridization between the $\mathrm{H}$ and the $\mathrm{Mg}$ states in the valence bands, with the lowest two valence bands having some $\mathrm{Mg} s$ and the highest two having some $\mathrm{Mg} p$ character, respectively. As in the case of $\mathrm{LiH}$ and $\mathrm{NaH}$, the valence bands have a dominant hydrogen character, however. The conduction bands have a mixed magnesium hydrogen character and the bottom of the conduction band has a considerable $\mathrm{Mg} 3 \mathrm{~s}$ contribution. $\mathrm{MgH}_{2}$ has a calculated indirect gap of $5.32 \mathrm{eV}$, see Table I, whereas the direct optical gap is $6.19 \mathrm{eV}$. The experimental optical gap obtained in Ref. 64 is $5.6 \pm 0.1 \mathrm{eV}$,
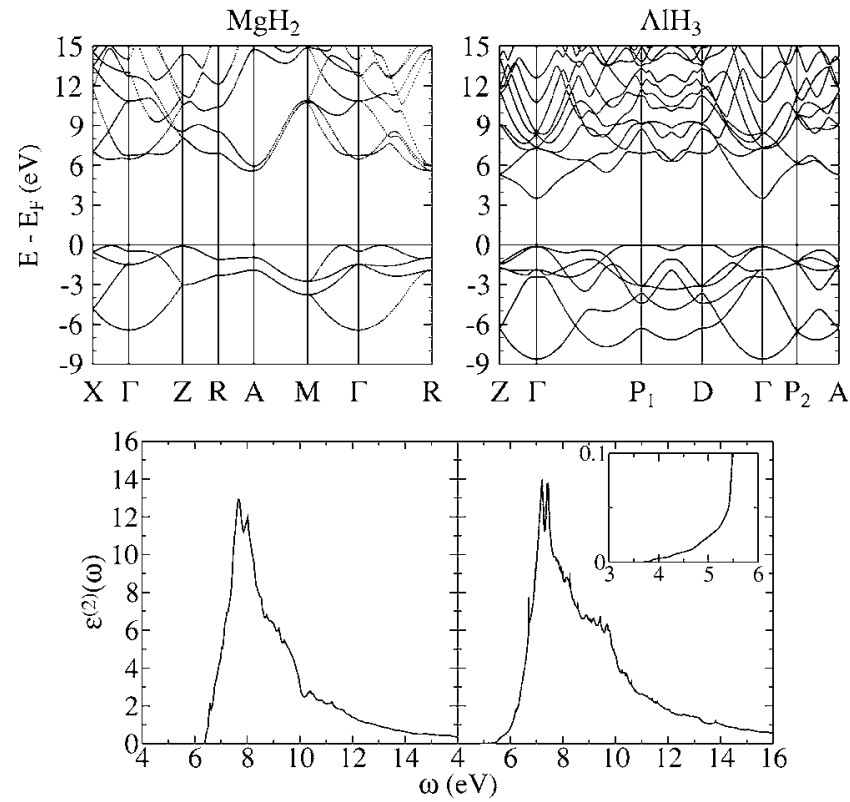

FIG. 2. Upper panels: electronic band structures of $\mathrm{MgH}_{2}$ and $\mathrm{AlH}_{3}$. The zero of the energy scale is at the top of the valence band. $P_{1}$ and $P_{2}$ correspond to the points $(0.5,-1,0.5)$ and $(0.5,0.5,0.5)$. Lower panels: imaginary parts of the directionally averaged macroscopic dielectric functions of $\mathrm{MgH}_{2}$ and $\mathrm{AlH}_{3}$. The calculated optical gaps of $\mathrm{MgH}_{2}$ and $\mathrm{AlH}_{3}$ are 6.19 and $3.54 \mathrm{eV}$, respectively.

which would indicate that our $G W$ result overestimates the gap by $10 \%$.

The lower panel of Fig. 2 shows the dielectric function of $\mathrm{MgH}_{2}$. It is in general agreement with that obtained in a recent GW/PAW calculation. ${ }^{65}$ The onset of optical transitions occurs almost at the same energy at various regions throughout the Brillouin zone, which results in a steep rise of the dielectric function and a peak close to $8 \mathrm{eV}$. At energies above $9 \mathrm{eV}$ transitions from the lower valence bands start to play a role, see, for instance, the interval $Z-M$ in the upper panel of Fig. 2. This results in a shoulder in the dielectric function at $\sim 9 \mathrm{eV}$. Finally, the shoulder at $\sim 11 \mathrm{eV}$ in the spectrum involves transitions to higher-lying conduction bands, associated with rather delocalized states having considerable Mg character.

\section{4. $\mathrm{AlH}_{3}$}

$\mathrm{AlH}_{3}$ has a rhombohedral structure with space group $R \overline{3} c$ and the $\mathrm{Al}, \mathrm{H}$ atoms in the $6 b, 18 e$ Wyckoff positions, respectively. The unit cell contains two formula units. The optimized lattice parameters are $a=4.49 \AA$ and $c=11.82 \AA$, with the $\mathrm{H}$ atoms at $x=0.623$. These values are in good agreement with the experimental values $a=4.45 \AA$, $c$ $=11.80 \AA$, and $x=0.628 .{ }^{70}$ The interatomic Al-Al distances in the $a b$ plane and along the $c$ axis are 4.45 and $3.24 \AA$, respectively. The aluminium atoms form a distorted facecentered structure, where each $\mathrm{Al}$ atom is octahedrally coordinated by $\mathrm{H}$ atoms with an $\mathrm{Al}-\mathrm{H}$ distance of $1.75 \AA$. Each $\mathrm{AlH}_{6}$ octahedron shares its corners with neighboring octahedra and each $\mathrm{H}$ atom at a corner forms a bridge between two $\mathrm{Al}$ atoms. Since these bridges are not linear, i.e., the Al-H-Al 
bond angle is $141^{\circ}$, the octahedra are tilted with respect to one another.

The band structure of $\mathrm{AlH}_{3}$ is shown in Fig. 2. There is hybridization between $\mathrm{H}$ and $\mathrm{Al}$ states, but the six valence bands are dominated by hydrogen, as are the valence bands of the other hydrides. In contrast to $\mathrm{MgH}_{2}, \mathrm{AlH}_{3}$ has a direct band gap, which is located at $\Gamma$. The band gap is $3.54 \mathrm{eV}$, which is notably smaller than the gap in the other hydrides discussed above. This is caused by a single conduction band that disperses to $\sim 2 \mathrm{eV}$ below the other conduction bands. This band has a large $\mathrm{Al} 3 s$ contribution.

The dielectric function of $\mathrm{AlH}_{3}$ is shown in the lower panel of Fig. 2. Although the optical response starts at the direct gap of $3.54 \mathrm{eV}$, see the inset in Fig. 2, it reaches significant values only above $6 \mathrm{eV}$. The weak response between 3.54 and $6 \mathrm{eV}$ is caused by the fact that only a single conduction band contributes with a low density of states. Moreover, since that band has $\mathrm{Al} 3 s$ character, whereas the valence bands have dominant $\mathrm{H}$ character, the oscillator strength of these transitions is small. The dielectric function rises sharply above $6 \mathrm{eV}$ and peaks above $7 \mathrm{eV}$. The spectrum has a distinct broad shoulder between 9 and $10 \mathrm{eV}$ and also some weaker shoulders at higher energies.

In order to interpret the dielectric function it is instructive to analyze the total density of states (DOS) and the local density of states (LDOS) of $\mathrm{AlH}_{3}$. These are shown in Fig. 3. The valence DOS has a sharp peak just below the Fermi level and two broad peaks at $\sim-2.5 \mathrm{eV}$ and $\sim-6 \mathrm{eV}$ below the Fermi level. These three peaks originate from, respectively, $3 s, 3 p$, and $3 d$ aluminium states hybridizing with the $1 s$ hydrogen states, as can be observed in the upper two panels of Fig. 3. In the solid the states are broadened into strongly overlapping bands. In the dielectric function transitions from the highest two of these valence peaks gives rise to the structure between 6 and $10 \mathrm{eV}$ in Fig. 2. The energy associated with transitions from the lowest valence peak is too high to give any significant contribution to the dielectric function.

Qualitatively the optical spectra of $\mathrm{AlH}_{3}$ and $\mathrm{MgH}_{2}$ show some similarity, despite the difference in structure between these materials. In both cases the dielectric function sharply rises above $6 \mathrm{eV}$ and peaks between 7 and $8 \mathrm{eV}$. The spectrum of $\mathrm{AlH}_{3}$ is broader due to a larger dispersion of the bands, reflecting the somewhat denser packing of the hydrogen atoms in this compound. From Fig. 1 one observes that the dielectric function of $\mathrm{NaH}$ also rises steeply above $6 \mathrm{eV}$ and peaks just above $7 \mathrm{eV}$. The spectrum of $\mathrm{NaH}$ is narrower than that of $\mathrm{MgH}_{2}$ and $\mathrm{AlH}_{3}$, reflecting the less dense packing of hydrogen atoms in this compound, which results in a smaller band dispersion. Only the spectrum of $\mathrm{LiH}$ is qualitatively different as it rises below $5 \mathrm{eV}$ in a broad shoulder. As discussed in Sec. III A 2, there is a significant contribution from the Li states in this case.

\section{B. Binary hydrides $\mathrm{Li}_{3} \mathrm{AlH}_{6}$ and $\mathrm{Na}_{3} \mathrm{AlH}_{6}$}

The optimized atomic positions of $\mathrm{Li}_{3} \mathrm{AlH}_{6}$ and $\mathrm{Na}_{3} \mathrm{AlH}_{6}$ are given in Table III. Both $\mathrm{Li}_{3} \mathrm{AlH}_{6}$ and $\mathrm{Na}_{3} \mathrm{AlH}_{6}$ consist of a stacking of $\mathrm{AlH}_{6}$ octahedra and alkali cations. The octahe-

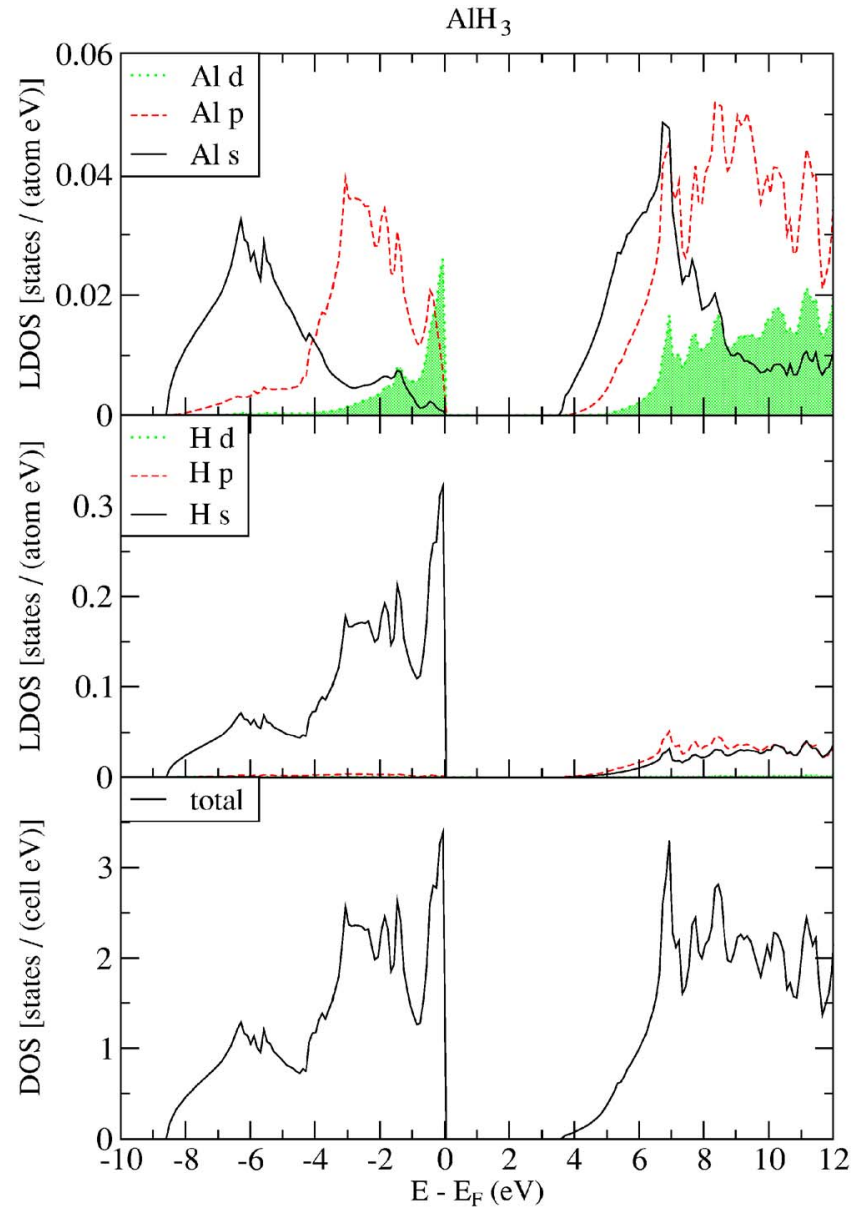

FIG. 3. (Color online) Local densities of states (LDOS) in atomic angular momentum projection; bottom panel: total density of states. The Fermi energy is at the top of the valence band.

dra are slightly distorted with Al-H distances of $1.75 \AA$ in $\mathrm{Li}_{3} \mathrm{AlH}_{6}$ and $1.78-1.80 \AA$ in $\mathrm{Na}_{3} \mathrm{AlH}_{6}$. These compounds contain a relatively large fraction of alkali cations. Since sodium atoms are larger than lithium atoms, the distance between the $\mathrm{AlH}_{6}$ octahedra in $\mathrm{Na}_{3} \mathrm{AlH}_{6}$ is considerably larger. The $\mathrm{Al}-\mathrm{Al}$ distance in $\mathrm{Na}_{3} \mathrm{AlH}_{6}$ is $5.59 \AA$, whereas in $\mathrm{Li}_{3} \mathrm{AlH}_{6}$ it is $4.88 \AA$. As for the simple hydrides discussed in Sec. III A 2, this size effect leads to noticeable differences in the electronic structure and the optical properties of $\mathrm{Li}_{3} \mathrm{AlH}_{6}$ and $\mathrm{Na}_{3} \mathrm{AlH}_{6}$.

The local electronic densities of states (LDOS) of both compounds is given in Fig. 4. As in $\mathrm{AlH}_{3}$ the valence bands have dominant hydrogen character, although there is $\mathrm{Al}$ character mixed in. The splitting into three peaks with approximate relative intensity 1:3:2 can be interpreted in terms of an octahedral ligand field splitting..$^{29,78}$ The peaks correspond, respectively, to the $3 s, 3 p$, and $3 d\left(e_{g}\right)$ aluminum states hybridizing with the $1 s$ hydrogen levels in the $\mathrm{AlH}_{6}$ octahedra. As can be observed in Fig. 4 the $s p d$ splitting in $\mathrm{Li}_{3} \mathrm{AlH}_{6}$ and $\mathrm{Na}_{3} \mathrm{AlH}_{6}$ is comparable, which reflects the similarity of the $\mathrm{AlH}_{6}$ octahedral structure in both compounds. Comparing to Fig. 3 one observes that the splitting is also comparable to that in $\mathrm{AlH}_{3}$, again suggesting the similarity in the octahedral structure. 
TABLE III. Optimized atomic positions in the binary hydrides. The labels " $1 \mathrm{a}$ " etc. refer to the Wyckoff positions. The cell parameters are taken from the references. The structures are in good agreement with previous experimental and theoretical, DFT-GGA (Refs. 8, 27-29, 36, and 71-78).

\begin{tabular}{|c|c|c|c|c|c|c|}
\hline Compound & $\begin{array}{l}\text { Space group } \\
\text { unit cell }\end{array}$ & & & $x$ & $y$ & $z$ \\
\hline \multirow[t]{5}{*}{$\mathrm{Li}_{3} \mathrm{AlH}_{6}$} & $R \overline{3}(148)^{\mathrm{a}}$ & $6 f$ & $\mathrm{Li}$ & 0.9329 & 0.4396 & 0.7512 \\
\hline & $a=5.64 \AA$ & $1 a$ & $\mathrm{Al}$ & 0 & 0 & 0 \\
\hline & $\alpha=91.4^{\circ}$ & $1 b$ & $\mathrm{Al}$ & $1 / 2$ & $1 / 2$ & $1 / 2$ \\
\hline & & $6 f$ & $\mathrm{H}$ & 0.7054 & 0.9287 & 0.0675 \\
\hline & & $6 f$ & $\mathrm{H}$ & 0.7941 & 0.5885 & 0.4518 \\
\hline \multirow[t]{6}{*}{$\mathrm{Na}_{3} \mathrm{AlH}_{6}$} & $P 2_{1} / n(14)^{\mathrm{b}}$ & $2 b$ & $\mathrm{Na}$ & 0 & 0 & $1 / 2$ \\
\hline & $a=5.51 \AA$ & $4 e$ & $\mathrm{Na}$ & 0.9908 & 0.4566 & 0.2553 \\
\hline & $b=5.67 \AA$ & $2 a$ & $\mathrm{Al}$ & 0 & 0 & 0 \\
\hline & $c=7.91 \AA$ & $4 e$ & $\mathrm{H}$ & 0.0983 & 0.0515 & 0.2125 \\
\hline & $\beta=89.9^{\circ}$ & $4 e$ & $\mathrm{H}$ & 0.2331 & 0.3327 & 0.5413 \\
\hline & & $4 e$ & $\mathrm{H}$ & 0.1583 & 0.2622 & 0.9347 \\
\hline \multirow[t]{6}{*}{$\mathrm{LiAlH}_{4}$} & $P 2{ }_{1} / c(14)^{\mathrm{c}}$ & $4 e$ & $\mathrm{Li}$ & 0.5727 & 0.4650 & 0.8254 \\
\hline & $a=4.84 \AA$ & $4 e$ & $\mathrm{Al}$ & 0.1395 & 0.2016 & 0.9314 \\
\hline & $b=7.81 \AA$ & $4 e$ & $\mathrm{H}$ & 0.1784 & 0.0988 & 0.7614 \\
\hline & $c=7.83 \AA$ & $4 e$ & $\mathrm{H}$ & 0.3561 & 0.3720 & 0.9775 \\
\hline & $\beta=112.1^{\circ}$ & $4 e$ & $\mathrm{H}$ & 0.2394 & 0.0816 & 0.1142 \\
\hline & & $4 e$ & $\mathrm{H}$ & 0.7953 & 0.2631 & 0.8714 \\
\hline \multirow[t]{3}{*}{$\mathrm{NaAlH}_{4}$} & $I 4_{1} / a(88)^{\mathrm{d}}$ & $4 b$ & $\mathrm{Na}$ & 0 & $1 / 4$ & $5 / 8$ \\
\hline & $a=5.01 \AA$ & $4 a$ & $\mathrm{Al}$ & 0 & $1 / 4$ & $1 / 8$ \\
\hline & $c=11.31 \AA$ & $16 f$ & $\mathrm{H}$ & 0.2354 & 0.3900 & 0.5454 \\
\hline \multirow[t]{4}{*}{$\mathrm{Mg}\left(\mathrm{AlH}_{4}\right)_{2}$} & $P \overline{3} m 1(164)^{\mathrm{e}}$ & $1 a$ & $\mathrm{Mg}$ & 0 & 0 & 0 \\
\hline & $a=5.23 \AA$ & $2 d$ & $\mathrm{Al}$ & $1 / 3$ & $2 / 3$ & 0.7064 \\
\hline & $c=6.04 \AA$ & $2 d$ & $\mathrm{H}$ & $1 / 3$ & $2 / 3$ & 0.4415 \\
\hline & & $6 i$ & $\mathrm{H}$ & 0.1680 & -0.1680 & 0.8118 \\
\hline
\end{tabular}

${ }^{\text {aReference }} 79$.

${ }^{b}$ Reference 29 .

${ }^{\mathrm{c}}$ Reference 8 .

The interaction between the octahedra in the solid results in a broadening of the three peaks. Unlike in $\mathrm{AlH}_{3}$ the $\mathrm{AlH}_{6}$ octahedra in $\mathrm{Li}_{3} \mathrm{AlH}_{6}$ and $\mathrm{Na}_{3} \mathrm{AlH}_{6}$ are not directly connected, which limits the interaction and the broadening. Therefore the three peaks remain nonoverlapping. One expects their widths to increase as the distance between the octahedra decreases and indeed the valence peaks in the DOS of $\mathrm{Li}_{3} \mathrm{AlH}_{6}$ are wider than in $\mathrm{Na}_{3} \mathrm{AlH}_{6}$. The conduction band of both compounds is rather featureless up to at least $22 \mathrm{eV}$. There is somewhat more cation $s$ character at the bottom of the conduction band in $\mathrm{Na}_{3} \mathrm{AlH}_{6}$, whereas the bonding in $\mathrm{Li}_{3} \mathrm{AlH}_{6}$ probably has a somewhat more covalent character, as in the simple hydrides.

The calculated band gaps are given in Table IV. As discussed in Sec. III A 1, DFT calculations severely underestimate the gap, with LDA giving a $\sim 0.5 \mathrm{eV}$ smaller value than GGA. The most important results are in the last two columns of Table IV, which give the $G W$ single-particle gap and the
${ }^{\mathrm{d}}$ Reference 80.

${ }^{\mathrm{e}}$ Reference 7.

direct optical gap. The single-particle gap is indirect in $\mathrm{Li}_{3} \mathrm{AlH}_{6}$ and direct in $\mathrm{Na}_{3} \mathrm{AlH}_{6}$. Previous $G W$ calculations on $\mathrm{Na}_{3} \mathrm{AlH}_{6}$, by Peles et al., ${ }^{29}$ agree well with our value. ${ }^{82}$ The fairly large difference between the gaps of $\mathrm{Li}_{3} \mathrm{AlH}_{6}$ and $\mathrm{Na}_{3} \mathrm{AlH}_{6}$ is striking. Moreover, the fact that the gap of $\mathrm{Li}_{3} \mathrm{AlH}_{6}$ is larger is somewhat counterintuitive. Naively one would expect that the larger broadening of the $\mathrm{AlH}_{6}$ octahedron levels discussed above would narrow the gap, since it leads to a larger valence-band width. The origin of the bandgap difference between $\mathrm{Li}_{3} \mathrm{AlH}_{6}$ and $\mathrm{Na}_{3} \mathrm{AlH}_{6}$ is discussed in Sec. IV.

The directionally averaged dielectric functions of $\mathrm{Li}_{3} \mathrm{AlH}_{6}$ and $\mathrm{Na}_{3} \mathrm{AlH}_{6}$ are shown in Fig. 5. The dielectric function of $\mathrm{Li}_{3} \mathrm{AlH}_{6}$ has a shoulder starting above $6 \mathrm{eV}$, a peak just above $8 \mathrm{eV}$ and a shoulder below $12 \mathrm{eV}$. Since the conduction-band DOS is rather uniform and featureless up to at least $22 \mathrm{eV}$, these features in the dielectric function can be directly linked to transitions from the three octahedron valence peaks. 


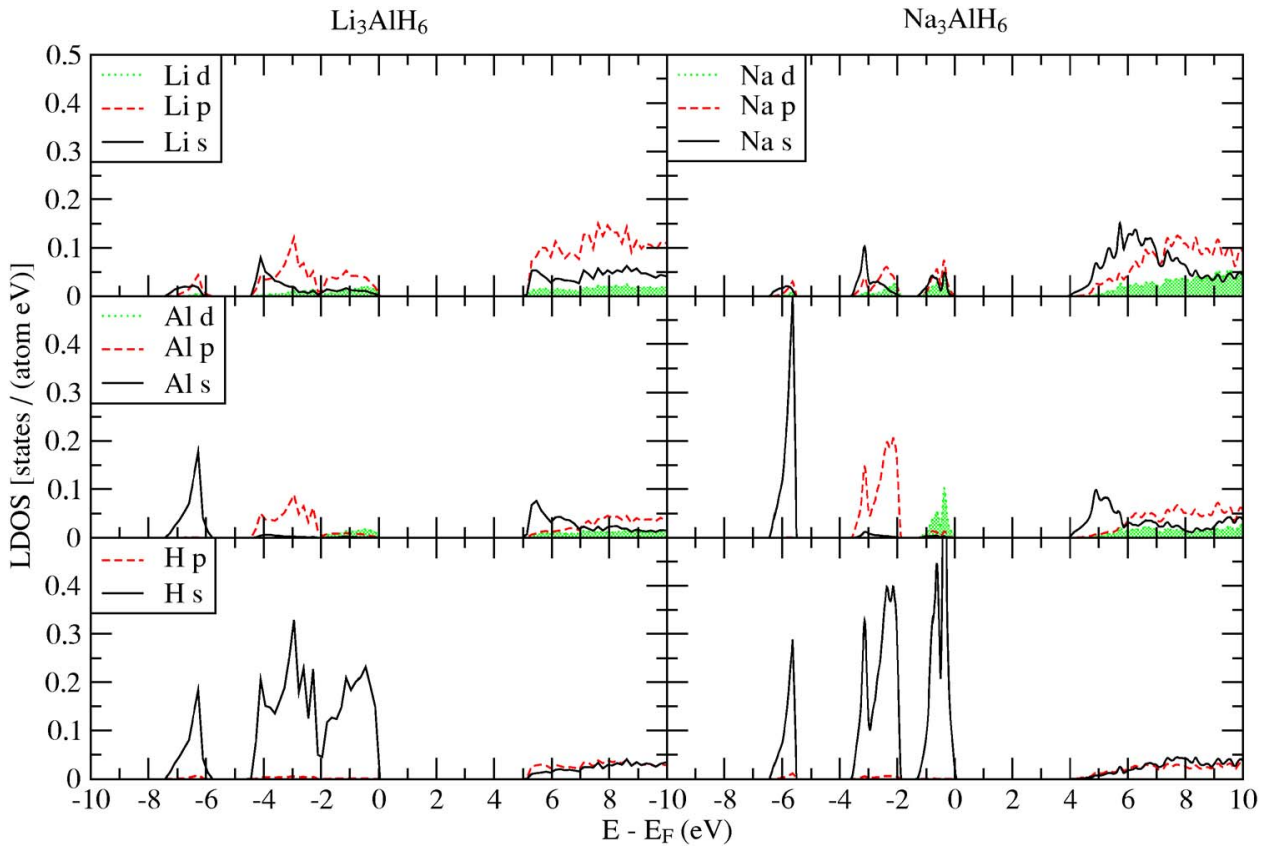

FIG. 4. (Color online) Local densities of states (LDOS) of $\mathrm{Li}_{3} \mathrm{AlH}_{6}$ and $\mathrm{Na}_{3} \mathrm{AlH}_{6}$ (Ref. 81). For clarity the area under the $d$ line is shaded. The Fermi energies are at the top of the valence band. The conduction-band DOS is almost constant up to at least $22 \mathrm{eV}$.
Despite the much smaller band gap of $\mathrm{Na}_{3} \mathrm{AlH}_{6}$ the dielectric function starts to increase appreciably only at an energy between 5 and $6 \mathrm{eV}$, which is not that much lower than in $\mathrm{Li}_{3} \mathrm{AlH}_{6}$. Transitions from the top two valence peaks give rise to the complicated pattern between 6 and $9 \mathrm{eV}$; transitions from the third valence peak gives the above $10 \mathrm{eV}$. Qualitatively these spectra have a resemblance to that of $\mathrm{AlH}_{3}$, see Fig. 2, reflecting the dominant role played by the $\mathrm{AlH}_{6}$ octahedra.

\section{Binary hydrides $\mathrm{LiAlH}_{4}, \mathrm{NaAlH}_{4}$, and $\mathrm{Mg}\left(\mathrm{AlH}_{4}\right)_{2}$}

The optimized structures of $\mathrm{LiAlH}_{4}, \mathrm{NaAlH}_{4}$, and $\mathrm{Mg}\left(\mathrm{AlH}_{4}\right)_{2}$ are given in Table III. For $\mathrm{LiAlH}_{4}$ and $\mathrm{NaAlH}_{4}$ we have used the experimental unit cells and optimized the atomic positions only; for $\mathrm{Mg}\left(\mathrm{AlH}_{4}\right)_{2}$ we have also optimized the size and shape of the unit cell. ${ }^{7}$ All three materials consist of a packing of $\mathrm{AlH}_{4}$ tetrahedra and alkali or alkaline-earth cations. The tetrahedra are slightly distorted and the Al-H distances vary from 1.62 to $1.65 \AA$ in $\mathrm{LiAlH}_{4}$, $1.64 \AA$ in $\mathrm{NaAlH}_{4}$, and from 1.60 to $1.62 \AA$ in $\mathrm{Mg}\left(\mathrm{AlH}_{4}\right)_{2}$.

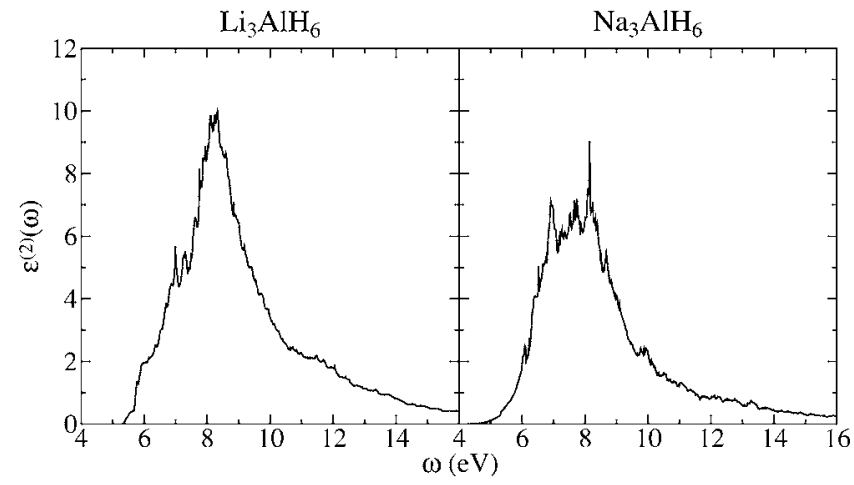

FIG. 5. Imaginary parts of the directionally averaged macroscopic dielectric functions of $\mathrm{Li}_{3} \mathrm{AlH}_{6}$ and $\mathrm{Na}_{3} \mathrm{AlH}_{6}$.
Unlike the two compounds discussed in the previous section, the volume fraction taken up by the cations is relatively small and the distance between the $\mathrm{AlH}_{4}$ tetrahedra is hardly influenced by the size of the cations. The Al-Al distance is $3.75 \AA$ in $\mathrm{LiAlH}_{4}, 3.78 \AA$ in $\mathrm{NaAlH}_{4}$, and $3.86 \AA$ in $\operatorname{Mg}\left(\mathrm{AlH}_{4}\right)_{2}$.

The LDOS of $\mathrm{LiAlH}_{4}, \mathrm{NaAlH}_{4}$, and $\mathrm{Mg}\left(\mathrm{AlH}_{4}\right)_{2}$ is shown in Fig. 6. As for the compounds discussed before, the valence bands have dominant hydrogen character with some Al character mixed in. The splitting into two peaks with approximate relative intensity $1: 3$ is due to a tetrahedral ligand field splitting of the $\mathrm{Al} 3 p$ and $3 s$ levels hybridized with $\mathrm{H} 1 s$ levels in $\mathrm{AlH}_{4} \cdot{ }^{29,77}$ The splitting is comparable in all three compounds, which reflects the similarity of the structure and bonding of the $\mathrm{AlH}_{4}$ tetrahedra in these compounds. The interaction between the tetrahedra causes a broadening of these levels in the solid. Figure 6 shows that also the resulting bandwidths of these valence states is comparable in all three compounds. Apparently the widths are not extremely sensitive to the details of the structure, which are quite different for $\mathrm{LiAlH}_{4}, \mathrm{NaAlH}_{4}$, and $\mathrm{Mg}\left(\mathrm{AlH}_{4}\right)_{2}$. They are sensitive to the distance between the tetrahedra, but this is comparable for the three compounds.

TABLE IV. Single-particle band gaps $E_{g}(\mathrm{eV})$ of the binary hydrides calculated with DFT (GGA and LDA) and $G W . E_{g}^{G W \text {,core }}$ refers to applying the correction of Eq. (3); opt ${ }^{G W}$ refers to the direct optical gap.

\begin{tabular}{lcccc}
\hline \hline & $E_{g}^{G G A}$ & $E_{g}^{L D A}$ & $E_{g}^{G W, \text { core }}$ & $\mathrm{opt}^{G W}$ \\
\hline $\mathrm{Li}_{3} \mathrm{AlH}_{6}$ & 3.65 & 3.13 & 5.10 & 5.31 \\
$\mathrm{Na}_{3} \mathrm{AlH}_{6}$ & 2.54 & 2.00 & 3.94 & 3.94 \\
$\mathrm{LiAlH}_{4}$ & 4.67 & 4.19 & 6.55 & 6.89 \\
$\mathrm{NaAlH}_{4}$ & 4.63 & 4.12 & 6.41 & 6.50 \\
$\mathrm{Mg}\left(\mathrm{AlH}_{4}\right)_{2}$ & 4.40 & 3.99 & 6.48 & 6.87 \\
\hline \hline
\end{tabular}




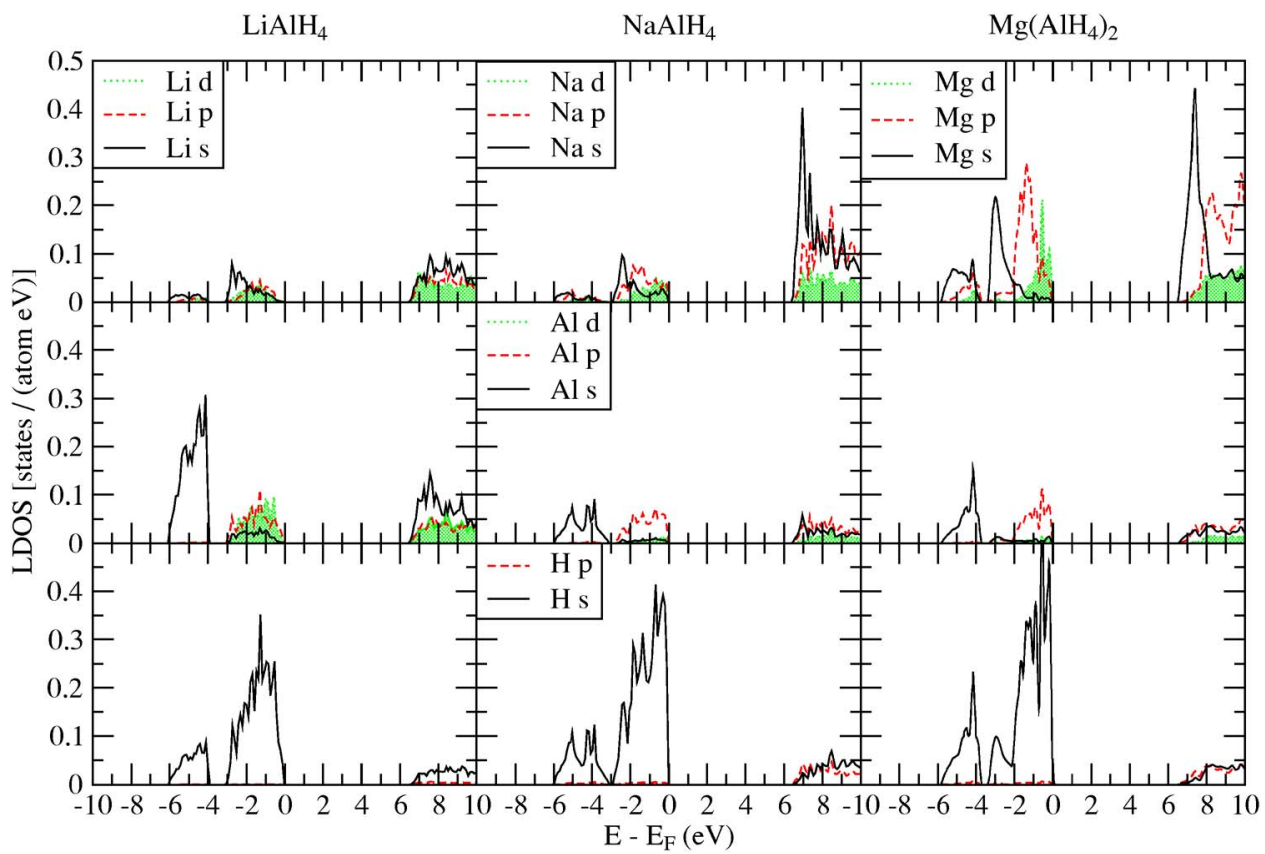

FIG. 6. (Color online) Local densities of states (LDOS) of $\mathrm{LiAlH}_{4}, \mathrm{NaAlH}_{4}$, and $\mathrm{Mg}\left(\mathrm{AlH}_{4}\right)_{2}$ (Ref. 81). For clarity the area under the $d$ line is shaded. The Fermi energies are at the top op of the valence band. The conduction band DOS is almost constant up to at least $22 \mathrm{eV}$.

Compared to the valence bands, the features in the conduction bands are less distinct. Both in $\mathrm{NaAlH}_{4}$ and in $\operatorname{Mg}\left(\mathrm{AlH}_{4}\right)_{2}$ the bottom of the conduction band has considerable $s$ character derived from the empty $3 s$ state of the cation. The conduction band in $\mathrm{LiAlH}_{4}$ is featureless. The LDOS on the $\mathrm{Al}$ atoms is very similar in $\mathrm{NaAlH}_{4}$ and in $\operatorname{Mg}\left(\mathrm{AlH}_{4}\right)_{2}$, but there are small differences with $\mathrm{LiAlH}_{4}$. There is significant $\mathrm{Al} d$ character in the valence band in the latter compound, and almost none in the other two compounds. In the conduction band of $\mathrm{LiAlH}_{4}$ there is a considerable Al $s$ contribution, and much less in the other compounds.

In order to evaluate these differences we have also calculated the LDOS for the $\mathrm{LiAlH}_{4}$ structure with the $\mathrm{Li}^{+}$ions replaced by a uniform positive background. The LDOS on the $\mathrm{Al}$ atoms then becomes very similar to that in the $\mathrm{NaAlH}_{4}$ and $\mathrm{Mg}\left(\mathrm{AlH}_{4}\right)_{2}$ compounds. All these features indicate that $\mathrm{NaAlH}_{4}$ and $\mathrm{Mg}\left(\mathrm{AlH}_{4}\right)_{2}$ can be considered as ionic compounds, i.e., as a packing of $\mathrm{AlH}_{4}{ }^{-}$anions and $\mathrm{Na}^{+}$or $\mathrm{Mg}^{2+}$ cations, whereas in $\mathrm{LiAlH}_{4}$ there may be a stronger covalent contribution.

The calculated band gaps are given in Table IV. The $G W$ single-particle band gaps of the three compounds are almost the same and also in the optical gaps there is very little difference. Previous $G W$ calculations on $\mathrm{NaAlH}_{4}$, by Peles et al. ${ }^{29}$ agree well with our value. ${ }^{83}$ This similarity indicates that the electronic structure around the band gap is foremost determined by the $\left(\mathrm{AlH}_{4}\right)^{-}$tetrahedra. The distances between these tetrahedra are similar in these three compounds and apparently the detailed differences in their packing are relatively unimportant.

This conclusion is strengthened by the dielectric function, which is shown in Fig. 7. The maximal dielectric response of $\operatorname{Mg}\left(\mathrm{AlH}_{4}\right)_{2}$ is somewhat smaller than that of $\mathrm{LiAlH}_{4}$ and $\mathrm{NaAlH}_{4}$, but the shape of the three curves is remarkably similar. The double peak structure of the valence band of the LDOS, which appears in all three compounds in Fig. 6, is almost washed out in the dielectric response. Transitions from the lowest valence band can be recognized only as a faint shoulder near $10 \mathrm{eV}$. It is then not surprising that the smaller differences between the LDOS of $\mathrm{LiAlH}_{4}$ and the other two compounds do not influence the dielectric functions much.

\section{DISCUSSION}

The electronic structure and the dielectric function of the binary compounds discussed in Secs. III B and III C are foremost determined by the lattice of $\left(\mathrm{AlH}_{6}\right)^{-}$octahedra and $\left(\mathrm{AlH}_{4}\right)^{-}$tetrahedra, respectively, whereas the cations have a minor influence. In this section we will discuss this proposition in more detail. The exact value of the band gap is not important in this discussion, only its relative variation with structure and composition. Since the latter is described qualitatively by DFT-GGA calculations, see Table IV, we will only use GGA results in this section.

We have calculated the dielectric functions of lattices of $\left(\mathrm{AlH}_{4}\right)^{-}$tetrahedra in the $\mathrm{LiAlH}_{4}, \mathrm{NaAlH}_{4}$ and $\mathrm{Mg}\left(\mathrm{AlH}_{4}\right)_{2}$ structures, but with the $\mathrm{Li}^{+}, \mathrm{Na}^{+}$, and $\mathrm{Mg}^{2+}$ cations replaced

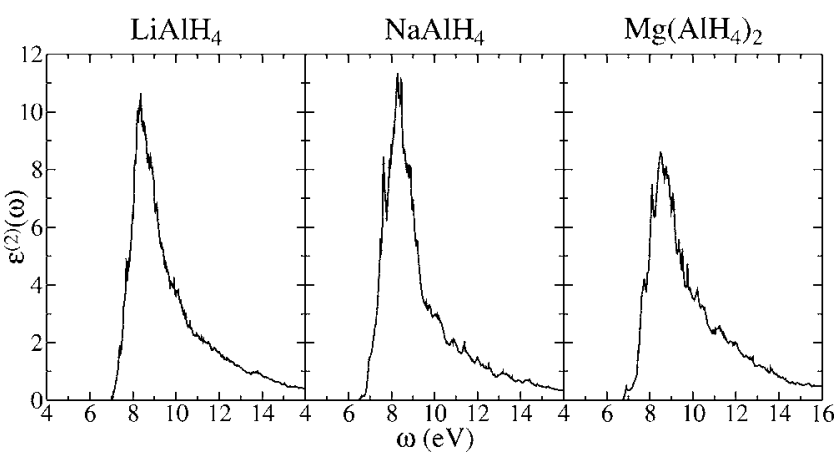

FIG. 7. Imaginary parts of the directionally averaged macroscopic dielectric functions of $\mathrm{LiAlH}_{4}, \mathrm{Na}_{3} \mathrm{AlH}_{6}$, and $\mathrm{Mg}\left(\mathrm{AlH}_{4}\right)_{2}$. 


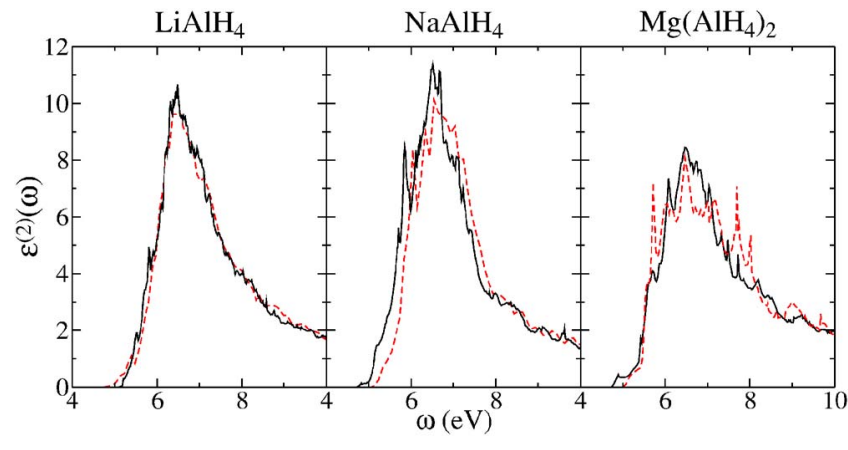

FIG. 8. (Color online) Dielectric functions of $\mathrm{MAlH}_{4}$ compounds (black, solid) and of the corresponding systems with $\mathrm{Li}^{+}$, $\mathrm{Na}^{+}$, and $\mathrm{Mg}^{2+}$ ions substituted by a uniform background charge (red, dashed). These results are based upon GGA calculations without scissors operator cerrection.

by a uniform positive background charge. The results are compared to the dielectric functions of the real compounds in Fig. 8. It can be observed that removing the cations in $\mathrm{LiAlH}_{4}$ hardly changes the dielectric function. Removing the cations in $\mathrm{NaAlH}_{4}$ results in a slight shift of the dielectric response to higher energies. This is related to the disappearance of the peak at the bottom of the conduction band, which has a sodium $s$ character, see the middle panel of Fig. 6. Also in $\mathrm{Mg}\left(\mathrm{AlH}_{4}\right)_{2}$ removing the cations results in small changes in the dielectric function only. These are mainly caused by the disappearance of the magnesium related peaks at the bottom of the conduction band and a resulting flattening of the conduction bands, see the right panel of Fig. 6 .

In conclusion, although removing the cations results in small changes in the conduction band, overall the dielectric function changes very little, which means that it is foremost determined by the lattice of $\left(\mathrm{AlH}_{4}\right)^{-}$anions. Such a behavior is not uncommon for ionic compounds. For instance, in alkali halides such as $\mathrm{NaCl}$ both the top of the valence band and the bottom of the conduction band are determined by the anion lattice. ${ }^{84,85}$

Going one step further one can correlate the relative size of the band gap with the distance between the anions. We will illustrate this using the DOS of $\operatorname{Mg}\left(\mathrm{AlH}_{4}\right)_{2}$, which is shown in Fig. 9(a). Replacing the $\mathrm{Mg}^{2+}$ ions by a uniform positive background does not change the DOS significantly, as can be observed in Fig. 9(b). In Figs. 9(c)-9(e) the cell parameters are increased while the geometry of the $\left(\mathrm{AlH}_{4}\right)^{-}$ tetrahedra is fixed. As the distance between the anions increases, the bandwidths of all bands decreases, but those of the valence bands decrease much more rapidly. At a large distance the DOS is essentially that of an isolated $\left(\mathrm{AlH}_{4}\right)^{-}$ tetrahedron, where the valence states are split into states of $s$ and $p$ symmetry due to the tetrahedral ligand field. The upper states of $p$ symmetry show a small splitting, since the tetrahedron has a small trigonal distortion. The gap between the highest valence state and the lowest conduction state in the isolated tetrahedron is only $\sim 0.5$ times the band gap in the solid, compare Figs. 9(b) and 9(e).

In general, the larger the distance between the anions, the smaller the gap. This result seems to be somewhat counterintuitive, as at the same time the valence- and conduction-

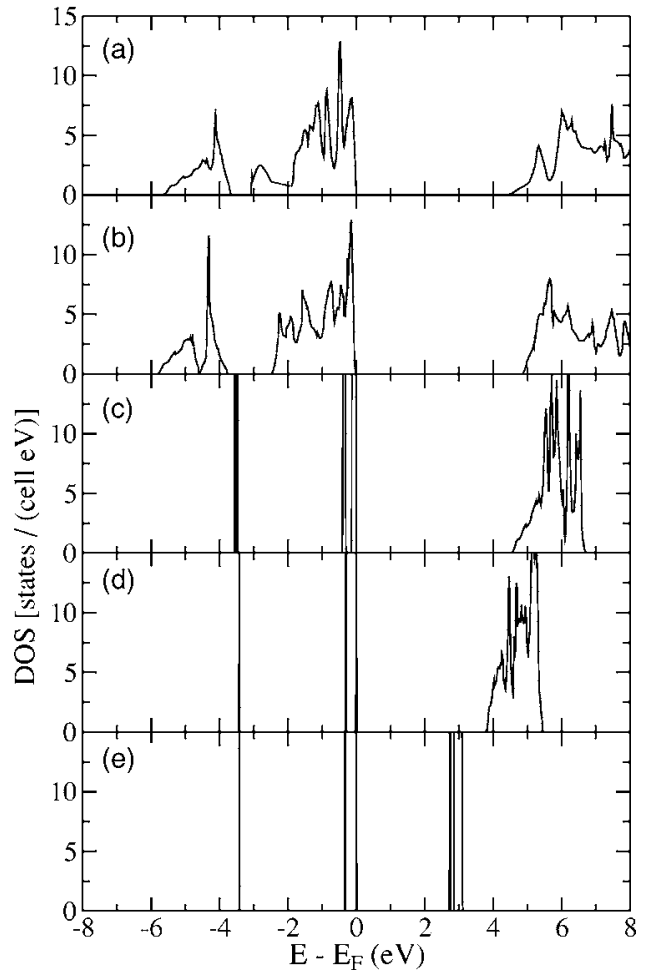

FIG. 9. GGA densities of state of (a) $\mathrm{Mg}\left(\mathrm{AlH}_{4}\right)_{2}$ and (b) with the $\mathrm{Mg}^{2+}$ ions replaced by a uniform background charge. While fixing the geometry of the $\left(\mathrm{AlH}_{4}\right)^{-}$ions, the lattice is expanded by a factor of 1,5 (c), 2 (d), and 5 (e).

band widths are decreasing and in general this would increase the gap. The result can be understood in terms of the electrostatic (Madelung) potential. ${ }^{86}$ Increasing the lattice constant, the electrostatic potential on the anions becomes less attractive to electrons, due to the less denser packing of the cations. The same argument also holds for a uniform positive background, i.e., an increasing lattice constant leads to a less attractive Madelung potential on the anions. All states on the anions experience this potential and increase their energy. The size of this shift, however, depends upon the degree of localization of the state. If a state is completely localized, the Madelung potential has a maximum effect. On the other hand, if a state is completely delocalized, its energy shift is zero, since the system as a whole is charge neutral.

The key point is that in our systems the valence states are much more localized than the conduction states. This is immediately evident from Figs. 9(b)-9(e), where the valenceband widths decrease much faster with an increasing lattice constant than the conduction-band widths. As a result, the more localized valence states increase their energy significantly faster with an increasing lattice constant than the conduction-band states. Since this effect is much larger than the effect of the decreasing bandwidths, increasing the lattice constant results in a smaller band gap.

This is quantified in Fig. 10, where the band gaps of the two, three, four, five, and six times expanded lattice are fitted to an expression $A e^{2} / d$, with $d$ the distance between the anions. The constant $A=1.57$ represents the difference in localization of the valence and conduction states. This simple 


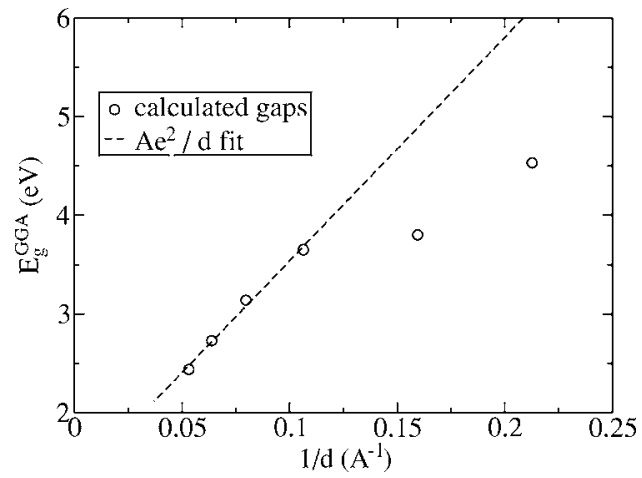

FIG. 10. Calculated GGA band gaps of the expanded $\left(\mathrm{AlH}_{4}\right)^{-}$ lattice (circles) fitted to $A e^{2} / d$ (dashed line), whith $d$ the distance between the anions; $A=1.57$.

model breaks down if the localization of the states strongly depends upon $d$, i.e., in the 1.5 and 2 times expanded lattice. It occurs if $d$ becomes sufficiently small, see Fig. 9(b).

This concept can be used to interpret the trend in the band gaps of the binary compounds, see Table IV. In $\mathrm{LiAlH}_{4}$, $\mathrm{NaAlH}_{4}$ and $\mathrm{Mg}\left(\mathrm{AlH}_{4}\right)_{2}$ the $\mathrm{Al}-\mathrm{Al}$ distance, which is a measure for the distance between the anions, is almost the same, so their band gaps are very close. The Al-Al distance in $\mathrm{Li}_{3} \mathrm{AlH}_{6}$ is much smaller than in $\mathrm{Na}_{3} \mathrm{AlH}_{6}$, which explains the larger band gap in the former compound.

\section{SUMMARY}

In this paper the electronic structures and dielectric functions of the simple hydrides $\mathrm{LiH}, \mathrm{NaH}, \mathrm{MgH}_{2}$, and $\mathrm{AlH}_{3}$, and the complex hydrides $\mathrm{Li}_{3} \mathrm{AlH}_{6}, \mathrm{Na}_{3} \mathrm{AlH}_{6}, \mathrm{LiAlH}_{4}, \mathrm{NaAlH}_{4}$, and $\mathrm{Mg}\left(\mathrm{AlH}_{4}\right)_{2}$, have been studied by first-principles calculations. The equilibrium structures of these compounds are obtained from DFT-GGA total-energy minimizations. $G W$ calculations within the QP approximation provide the singleparticle excitation energies, i.e., the electronic band structures. We use the $G_{0} W_{0}$ approximation based upon LDA wave functions and eigenvalues. The difference between the dispersions of the $G W$ and the GGA bands is less than $10 \%$. Therefore the band structures are well represented by GGA band structures that are corrected by applying a scissors operator between occupied and unoccupied states in order to obtain the $G W$ band gap. From the single-particle wave functions we then calculate the directionally averaged dielectric functions within RPA, neglecting exciton effects. We also neglect local-field effects, but from calculations on static dielectric constants we conclude that this is a reasonable approximation.
All compounds are large gap insulators with band gaps that vary from $3.5 \mathrm{eV}$ in $\mathrm{AlH}_{3}$ to $6.5 \mathrm{eV}$ in the $\mathrm{MAlH}_{4}$ compounds. In all cases the valence bands are dominated by the hydrogen atoms, whereas the conduction bands have mixed contributions from hydrogen and metal cation states. The band gap in $\mathrm{LiH}, \mathrm{AlH}_{3}$, and $\mathrm{Na}_{3} \mathrm{AlH}_{6}$ is direct, whereas in all the other compounds it is indirect. The optical response of most compounds is qualitatively similar, notwithstanding sizeable differences in their band structure and band gap. The dielectric function $\varepsilon^{(2)}(\omega)$ rises sharply at photon energies corresponding to $\sim 6 \mathrm{eV}$, and around $\sim 8 \mathrm{eV}$ it has a strong peak reaching values in the range 10-15. In the direct gap materials $\varepsilon^{(2)}(\omega)$ has a weak tail going to lower energies. Between $\sim 8$ and $\sim 12 \mathrm{eV}, \varepsilon^{(2)}(\omega)$ gradually decreases to a value $\leqslant 2$ at $12 \mathrm{eV}$. Most of the materials specific optical information can be found in this energy range, albeit in the form of relatively weak shoulders in $\varepsilon^{(2)}(\omega)$.

The electronic structure and the optical properties of the aluminium compounds can be interpreted in terms of aluminium hydride complexes, i.e., $\mathrm{AlH}_{6}$ octahedra in $\mathrm{AlH}_{3}$, $\mathrm{Li}_{3} \mathrm{AlH}_{6}$, and $\mathrm{Na}_{3} \mathrm{AlH}_{6}$, and $\mathrm{AlH}_{4}$ tetrahedra in $\mathrm{LiAlH}_{4}$, $\mathrm{NaAlH}_{4}$. Explicit calculations on lattices of these complexes, without the $\mathrm{Li}, \mathrm{Na}$, and $\mathrm{Mg}$ cations, show that the latter have a relatively small effect on the DOS and on the optical response. The distance between the $\left(\mathrm{AlH}_{4}\right)^{-}$tetrahedra in $\mathrm{LiAlH}_{4}, \mathrm{NaAlH}_{4}$, and $\mathrm{Mg}\left(\mathrm{AlH}_{4}\right)_{2}$ is almost the same. Since the interaction between the tetrahedra is then similar, this explains why the optical spectra of these compounds are very similar.

The same reasoning can be applied to $\mathrm{Li}_{3} \mathrm{AlH}_{6}$ and $\mathrm{Na}_{3} \mathrm{AlH}_{6}$ in terms of a lattice of $\left(\mathrm{AlH}_{6}\right)^{3-}$ octahedra. However, the distance between the octahedra is smaller in the $\mathrm{Li}$ compound because of the smaller size of the cation. The band gap then becomes larger, which can be understood from the influence of the increased Madelung potential on the more localized valence states.

\section{ACKNOWLEDGMENTS}

The authors wish to thank R. A. de Groot and P. J. Kelly for helpful discussions, J. Furthmüller for the use of his optics package, and G. Kresse for making the linear-response routines in VASP available. This work is part of the research programs of Advanced Chemical Technologies for Sustainability (ACTS) and the Stichting voor Fundamenteel Onderzoek der Materie (FOM). The use of supercomputer facilities was sponsored by the Stichting Nationale Computerfaciliteiten (NCF). These institutions are financially supported by Nederlandse Organisatie voor Wetenschappelijk Onderzoek (NWO).
${ }^{1}$ See, e. g., F. Schüth, B. Bogdanovic, and M. Felderhoff, Chem. Commun. (Cambridge) 20, 2249 (2004).

${ }^{2}$ R. Griessen and A. Driessen, Phys. Rev. B 30, 4372 (1984).

${ }^{3}$ K. Bohmhammel, U. Wolf, G. Wolf, and E. Königsberger, Ther- mochim. Acta 337, 195 (1999).

${ }^{4}$ C. Wolverton, V. Ozolins, and M. Asta, Phys. Rev. B 69, 144109 (2004).

${ }^{5}$ B. Bogdanovic and M. Schwickardi, J. Alloys Compd. 253, 1 
(1997).

${ }^{6}$ B. Bogdanovic, M. Felderhoff, S. Kaskel, A. Pommerin, K. Schlichte, and F. Schuth, Adv. Math. 15, 1012 (2003).

${ }^{7}$ M. J. van Setten, G. A. de Wijs, V. A. Popa, and G. Brocks, Phys. Rev. B 72, 073107 (2005).

${ }^{8}$ O. M. Løvvik, S. M. Opalka, H. W. Brinks, and B. C. Hauback, Phys. Rev. B 69, 134117 (2004).

${ }^{9}$ O. M. Løvvik and P. N. Molin, Phys. Rev. B 72, 073201 (2005).

${ }^{10}$ A. Andreasen, T. Vegge, and A. S. Pedersen, J. Solid State Chem. 178, 3672 (2005).

${ }^{11}$ M. Mamatha, C. Weidenthaler, A. Pommerin, M. Felderhoff, and F. Schuth, J. Alloys Compd. 416, 303 (2006).

${ }^{12}$ T. N. Dymova, D. P. Aleksandrov, V. N. Konoplev, T. A. Silina, and A. S. Sizareva, Russ. J. Coord. Chem. 20, 263 (1994).

${ }^{13}$ R. Gremaud, A. Borgschulte, W. Lohstroh, H. Schreuders, A. Züttel, B. Dam, and R. Griessen, J. Alloys Compd. 404, 775 (2005).

${ }^{14}$ C. H. Olk, G. G. Tibbetts, D. Simon, and J. J. Moleski, J. Appl. Phys. 94, 720 (2003).

${ }^{15}$ J. N. Huiberts, R. Griessen, J. H. Rector, R. J. Wijnaarden, J. P. Dekker, D. G. de Groot, and N. J. Koeman, Nature (London) 380, 231 (1996).

${ }^{16}$ M. Kremers, N. J. Koeman, R. Griessen, P. H. L. Notten, R. Tolboom, P. J. Kelly, and P. A. Duine, Phys. Rev. B 57, 4943 (1998).

${ }^{17}$ J. W. J. Kerssemakers, S. J. van der Molen, N. J. Koeman, R. Gunther, and R. Griessen, Nature (London) 406, 489 (2000).

${ }^{18}$ T. J. Richardson, J. L. Slack, R. D. Armitage, R. Kostecki, B. Farangis, and M. D. Rubin, Appl. Phys. Lett. 78, 3047 (2001).

${ }^{19}$ W. Lohstroh, R. J. Westerwaal, B. Noheda, S. Enache, I. A. M. E. Giebels, B. Dam, and R. Griessen, Phys. Rev. Lett. 93, 197404 (2004).

${ }^{20}$ W. Lohstroh, R. J. Westerwaal, J. L. M. van Mechelen, C. Chacon, E. Johansson, B. Dam, and R. Griessen, Phys. Rev. B 70, 165411 (2004).

${ }^{21}$ P. Kumar and L. K. Malhotra, Thin Solid Films 491, 270 (2005).

${ }^{22}$ A. C. Lokhorst, B. Dam, I. A. M. Giebels, M. S. Welling, W. Lohstroh, and R. Griessen, J. Alloys Compd. 404, 465 (2005).

${ }^{23}$ J. A. Dilts and E. C. Ashby, Inorg. Chem. 11, 1230 (1972).

${ }^{24}$ T. N. Dymova, V. N. Konoplev, D. P. Aleksandrov, A. S. Sizareva, and T. A. Silina, Koord. Khim. 21, 175 (1995).

${ }^{25}$ K. J. Gross, E. H. Majzoub, and S. W. Spangler, J. Alloys Compd. 356, 423 (2003).

${ }^{26}$ A. Züttel, S. Rentsch, P. Fischer, P. Wenger, P. Sudan, P. Mauron, and C. Emmenegger, J. Alloys Compd. 356, 515 (2003).

${ }^{27}$ M. Fichtner, J. Engel, O. Fuhr, A. Gloss, O. Rubner, and R. Ahlrichs, Inorg. Chem. 42, 7060 (2003).

${ }^{28}$ M. E. Arroyo y de Dompablo and G. Ceder, J. Alloys Compd. 364, 6 (2003).

${ }^{29}$ A. Peles, J. A. Alford, Zhu Ma, Li Yang, and M. Y. Chou, Phys. Rev. B 70, 165105 (2004).

${ }^{30}$ J. P. Perdew, J. A. Chevary, S. H. Vosko, K. A. Jackson, M. R. Pederson, D. J. Singh, and C. Fiolhais, Phys. Rev. B 46, 6671 (1992).

${ }^{31}$ G. Kresse and D. Joubert, Phys. Rev. B 59, 1758 (1999).

${ }^{32}$ P. E. Blochl, Phys. Rev. B 50, 17953 (1994).

${ }^{33}$ G. Kresse and J. Furthmüller, Phys. Rev. B 54, 11169 (1996).

${ }^{34}$ G. Kresse and J. Furthmüller, Comput. Mater. Sci. 6, 15 (1996).

${ }^{35}$ G. Kresse and J. Hafner, Phys. Rev. B 47, 558 (1993).

${ }^{36}$ P. Vajeeston, P. Ravindran, R. Vidya, H. Fjellvåg, and A. Kjek- shus, Cryst. Growth Des. 4, 471 (2004).

${ }^{37}$ O. M. Løvvik, O. Swang, and S. M. Opalka, J. Mater. Res. 20, 3199 (2005).

${ }^{38}$ F. Aryasetiawan and O. Gunnarsson, Rep. Prog. Phys. 61, 237 (1998).

${ }^{39}$ G. Onida, L. Reining, and A. Rubio, Rev. Mod. Phys. 74, 601 (2002).

${ }^{40}$ W. G. Aulbur, L. Jonsson, and J. W. Wilkins, Solid State Phys., Adv. Res. Appl. 54, 1 (2000).

${ }^{41}$ J. P. Perdew and A. Zunger, Phys. Rev. B 23, 5048 (1981).

${ }^{42}$ M. S. Hybertsen and S. G. Louie, Phys. Rev. B 34, 2920 (1986).

${ }^{43}$ R. W. Godby, M. Schlüter, and L. J. Sham, Phys. Rev. B 37, 10159 (1988).

${ }^{44}$ The QP energies $\epsilon_{n \mathbf{k}}$ are complex. The real parts comprise the band structure and are used as single-particle excitation energies. The imaginary parts give the inverse QP lifetimes.

${ }^{45}$ M. van Schilfgaarde, T. Kotani, and S. Faleev, Phys. Rev. Lett. 96, 226402 (2006).

${ }^{46}$ P. van Gelderen, P. A. Bobbert, P. J. Kelly, and G. Brocks, Phys. Rev. Lett. 85, 2989 (2000).

${ }^{47}$ P. van Gelderen, P. A. Bobbert, P. J. Kelly, G. Brocks, and R. Tolboom, Phys. Rev. B 66, 075104 (2002).

${ }^{48}$ V. A. Popa, G. Brocks, and P. J. Kelly, cond-mat/0507013 (unpublished).

${ }^{49}$ N. Troullier and J. L. Martins, Phys. Rev. B 43, 1993 (1991).

${ }^{50}$ H. N. Rojas, R. W. Godby, and R. J. Needs, Phys. Rev. Lett. 74, 1827 (1995).

${ }^{51}$ M. M. Rieger, L. Steinbeck, I. D. White, H. N. Rojas, and R. W. Godby, Comput. Phys. Commun. 117, 211 (1999).

${ }^{52}$ J. W. van der Horst, P. A. Bobbert, P. H. L. de Jong, M. A. J. Michels, G. Brocks, and P. J. Kelly, Phys. Rev. B 61, 15817 (2000).

${ }^{53}$ V. G. Plekhanov, V. A. Pustovarov, A. A. O`Konnel-Bronin, T. A. Betenekova, and S. O. Cholakh, Sov. Phys. Solid State 18, 2438 (1976).

${ }^{54}$ S. Baroni, G. P. Parravicini, and G. Pezzica, Phys. Rev. B 32, 4077 (1985).

${ }^{55}$ S. L. Adler, Phys. Rev. 126, 413 (1962).

${ }^{56}$ N. Wiser, Phys. Rev. 129, 62 (1963).

${ }^{57}$ R. Del Sole and R. Girlanda, Phys. Rev. B 48, 11789 (1993).

${ }^{58}$ M. Gajdos, K. Hummer, G. Kresse, J. Furthmüller, and F. Bechstedt, Phys. Rev. B 73, 045112 (2006).

${ }^{59}$ B. Arnaud and M. Alouani, Phys. Rev. B 63, 085208 (2001).

${ }^{60}$ B. Adolph, J. Furthmüller, and F. Bechstedt, Phys. Rev. B 63, 125108 (2001).

${ }^{61}$ S. Lebègue, M. Alouani, B. Arnaud, and W. E. Pickett, Europhys. Lett. 63, 562 (2003).

${ }^{62}$ S. Lebègue, B. Arnaud, M. Alouani, and P. E. Bloechl, Phys. Rev. B 67, 155208 (2003).

${ }^{63}$ E. L. Shirley, Phys. Rev. B 58, 9579 (1998).

${ }^{64}$ J. Isidorsson, I. A. M. E. Giebels, H. Arwin, and R. Griessen, Phys. Rev. B 68, 115112 (2003).

${ }^{65}$ C. Moysés Araújo, S. Lebègue, O. Eriksson, B. Arnaud, M. Alouani, and R. Ahuja, J. Appl. Phys. 98, 096106 (2005).

${ }^{66}$ P. Vajeeston, P. Ravindran, A. Kjekshus, and H. Fjellvåg, Phys. Rev. Lett. 89, 175506 (2002).

${ }^{67}$ J. L. Martins, Phys. Rev. B 41, 7883 (1990).

${ }^{68}$ M. Bortz, B. Bertheville, G. Böttger, and K. Yvon, J. Alloys Compd. 287, L4 (1999).

${ }^{69}$ R. Yu and P. K. Lam, Phys. Rev. B 37, 8730 (1988). 
${ }^{70}$ J. W. Turley and H. W. Rinn, Inorg. Chem. 8, 18 (1969).

${ }^{71}$ E. Rönnebro, D. Noréus, K. Kadir, A. Reiser, and B. Bogdanovic, J. Alloys Compd. 299, 101 (2000).

${ }^{72}$ S. C. Chung and H. Morioka, J. Alloys Compd. 372, 92 (2004)

${ }^{73}$ A. Aguayo and D. J. Singh, Phys. Rev. B 69, 155103 (2004).

${ }^{74}$ P. Vajeeston, P. Ravindran, R. Vidya, H. Fjellvåg, and A. Kjekshus, Appl. Phys. Lett. 82, 2257 (2003).

${ }^{75}$ B. C. Hauback, H. W. Brinks, and H. Fjellvåg, J. Alloys Compd. 346, 184 (2002).

${ }^{76}$ Y. Song, R. Singh, and Z. X. Guo, J. Phys. Chem. B 110, 6906 (2006).

${ }^{77}$ P. Vajeeston, P. Ravindran, R. Vidya, H. Fjellvåg, and A. Kjekshus, Phys. Rev. B 68, 212101 (2003).

${ }^{78}$ P. Vajeeston, P. Ravindran, A. Kjekshus, and H. Fjellvåg, Phys. Rev. B 69, 020104(R) (2004).

${ }^{79}$ H. W. Brinks and B. C. Hauback, J. Alloys Compd. 354, 143 (2003).

${ }^{80}$ B. C. Hauback, H. W. Brinks, C. M. Jensen, K. Murphy, and A. J.
Maeland, J. Alloys Compd. 358, 142 (2003).

${ }^{81} \mathrm{We}$ use atomic radii $0.79,1.23,1.59,1.36$, and $0.81 \AA$ for $\mathrm{H}, \mathrm{Li}$, $\mathrm{Na}, \mathrm{Mg}$, and $\mathrm{Al}$, respectively.

${ }^{82} \mathrm{In}$ Ref. 29 a value of $4.6 \mathrm{eV}$ is given for the single-particle gap of $\mathrm{Na}_{3} \mathrm{AlH}_{6}$. This value is obtained by applying a $G_{0} W_{0}$ shift to the GGA band gap, whereas we apply the shift to the LDA gap. The difference with our value of $3.94 \mathrm{eV}$ then mainly reflects the difference between the LDA and GGA gaps, see Table IV. Experience indicates that applying a $G_{0} W_{0}$ shift to the LDA gap generally results in a value that is within $10 \%$ of the experimental single-particle gap, see Refs. 38 and 39.

${ }^{83}$ In Ref. 29 a value of $6.9 \mathrm{eV}$ is given for the single-particle gap of $\mathrm{NaAlH}_{4}$. Again this value is obtained by applying a $G_{0} W_{0}$ shift to the GGA band gap.

${ }^{84}$ P. K. de Boer and R. A. de Groot, Am. J. Phys. 67, 443 (1999).

${ }^{85}$ P. K. de Boer and R. A. de Groot, Eur. Phys. J. B 4, 25 (1998).

${ }^{86}$ J. C. Slater and W. Shockley, Phys. Rev. 50, 705 (1936). 